\title{
What's the score? Assessing the impacts and outcomes of lifelong learning
}

\section{Stephen Roche ${ }^{1}$}

Published online: 18 September 2018

(C) Springer Nature B.V. and UNESCO Institute for Lifelong Learning 2018

Assessing the extent of learning, never mind its impact or outcome, is a thorny challenge. Schools face the problem that students learn differently, both in terms of style and pace. Universities and colleges face the problem of overreliance on examinations, which are inadequate to assess much of the knowledge and many of the skills required after graduation. In adult and non-formal education, the issue is further complicated by the fact that the desired outcomes are often more complex and less immediate than those of formal education. A primary school pupil hopes to achieve the necessary score to proceed to their preferred form of secondary education; the secondary student studies hard to achieve a score that will allow them to enter the workforce, higher education or vocational training; while the vocational or university student pursues a score that will translate into a respected qualification, which in turn may secure entry into their chosen profession. By contrast, the adult learner balances a variety of hopes and desires: from acquiring knowledge for its own sake, to career progression, increased income, improved well-being, social contact, personal development, community engagement, and much more. In fact, one of the great attractions of adult learning is that we embark on the journey without quite knowing the destination. In the words of Manuel London,

Learning can bring about change by creating new capabilities and opening the door to new and unexpected opportunities (London 2011, p. 1). ${ }^{1}$

It is frequently a catalyst for positive change, provoking small changes in behaviour that, incrementally, transform a person's life.

This issue of the International Review of Education - Journal of Lifelong Learning (IRE) features six articles, all of which look at ways of assessing the impact of various modes of lifelong learning - on individuals, families, communities and society as a whole. Assessment is often seen as the Achilles heel of

\footnotetext{
${ }^{1}$ London, M. (2011). Lifelong Learning: Introduction. In M. London (Ed), The Oxford Handbook of Lifelong Learning [online]. Oxford: Oxford University Press. DOI: https://doi.org/10.1093/oxfordhb/ 9780195390483.013.0013.
}

Stephen Roche

s.roche@unesco.org

1 UNESCO Institute for Lifelong Learning, Hamburg, Germany 
lifelong learning; whereas it is an integral part of formal education - in the form of systems designed to evaluate whether students have attained the knowledge necessary to either continue to the next level, or merit award of a qualification more nuanced approaches to evaluating success and impact are needed in adult, non-formal, informal and community learning. This, however, need not be seen as a weakness. In fact, formal education has much to learn from efforts to measure impact in lifelong learning. One lesson is that we must not equate education with the mere acquisition of knowledge, skills or attitudes. Perhaps, to paraphrase the Delors report $^{2}$ of the United Nations Educational, Scientific and Cultural Organization (UNESCO), the most important element of any education is that it engenders the desire, confidence and ability to continue learning.

The advancement of the lifelong learning paradigm has coincided with accelerated social and economic change. Most education systems were first developed in the nineteenth century, with the intention of equipping the masses with the knowledge and skills to work in expanded state bureaucracies and private industries. Pre-industrial societies had little need of literate masses; in fact, literacy threatened acquiescence. Just as industrial economies and populous urbanised societies required more skilled and educated members, the post-industrial economies and knowledge societies that are currently emerging require ever greater numbers of people equipped with the ability and autonomy to learn and adapt.

What we have seen in the last generation goes far beyond a mere change in the knowledge requirements of the workplace; it is a transformation of the very meanings of knowledge, work and workplace. Just a few decades ago, a physician's work rested principally on a combination of bedside manner (ability to elicit patient data) and retained knowledge (what s/he learned in medical school, augmented by experience and occasional reference). Today, most doctors regularly attend conferences, meet pharmaceutical representatives, peruse medical journals and conduct research multiple times a day (often in front of their patients). Indeed, the very term "research" is an interesting marker of change. A generation ago, research was an activity conducted - and indeed a word used - by a select few; scientists, journalists, students. Yet the average citizen of the Internet Age is a frequent researcher, adept at searching for and processing information to satisfy a wide variety of needs and whims.

Where once there existed a clear divide between the phases of education and work, it is no longer possible to imagine a single profession in which a skill set acquired in one's youth suffices for close to half a century. We have got used to the idea that certain professions - software engineer or physician, for example - require constant updating of skills and knowledge. Yet, they were merely in the vanguard. We are fast approaching a point where learning and work are inseparable, where the term "unskilled work" is redundant, and where smart technologies replace human labour in most manual roles. Some hope this development will result in the "necessary utopia" envisaged by Jacques Delors, others fear it will usher in the

\footnotetext{
${ }^{2}$ Delors, J., et al. (1998). Learning: The treasure within. Report to UNESCO of the International Commission on Education for the twenty-first century. Paris: UNESCO. Retrieved 7 September 2018 from http://www.unesdoc.unesco.org/images/0010/001095/109590eo.pdf.
} 
class-based dystopia imagined by Aldous Huxley (2007 [1932]). ${ }^{3}$ Perhaps, like all revolutions in human activity since we first adopted farming, its principal outcome will be even greater role differentiation and the further privileging of cognitive work.

\section{(1) Lifelong learning - lifelong returns? A new theoretical framework for the analysis of civic returns on adult learning}

Education has long been associated with a wide range of positive outcomes, from the lofty (building character, instilling culture) to the practical (enhancing employability). Given the current obsession among governments and other education funders to quantify and measure those outcomes, the emphasis has rested on economic returns, because, in a sense, these are the low-hanging fruit, with plenty of data that are easy to measure and compare. But excessive focus on the monetary benefits of learning tends to obscure and distort the bigger picture by ignoring less tangible returns such as increased individual well-being or social cohesion. While much of the previous research on this issue has focused on earlylife-phase education in schools or universities, there has been a notable shift in recent years towards examining the many ways adult learning enhances quality of life and promotes positive social values. One of the weaknesses of this research is measurement. Whereas numerous studies have measured the economic benefits of higher education, and some have yielded empirical evidence of positive outcomes, it is hard to prove a causal link, or even a correlation, between adult learning and various non-economic benefits.

The authors of this article - Ina Elisabeth Rüber, Sai-Lila Rees and Bernhard Schmidt-Hertha - focus on a single non-economic benefit, civic participation. This includes specific activities such as voting and volunteering, as well as attitudes such as trust and support for democratic values. They address the problem of measurement by confining their review of 13 empirical studies to what they describe as "hard factors" of civic participation - mainly engagement in volunteering and community associations. All of the studies reviewed in this article suggest a positive association between adult learning and civic engagement. The authors go further; by distilling the cumulative findings, they identify five mechanisms by which adult learning leads to active civic participation: by creating the precondition of economic security; by bestowing relevant qualifications and raising awareness of the benefits of civic engagement; by strengthening relevant personality traits; by generating supportive values and attitudes; and by expanding personal networks and providing access to new communities. The authors stop short of claiming causality, but demonstrate clear correlation between adult learning and civic engagement, and in isolating the five mechanisms, propose a new theoretical framework to guide further research.

\footnotetext{
${ }^{3}$ Huxley, A. (2007 [1932]). Brave new world. Toronto: Vintage Canada.
} 


\section{(2) Mutualising the university: Achieving community impact through an ecosystem}

The focus on economic returns distorts not only our view of education's impact on the individual, but also of its benefit to the community. For example, in a market model, students become consumers, the university a service provider, and every other relationship (e.g. to the state, the private sector, the local community, and alumni) comes to be viewed through a monetary, cost-benefit lens. This misrepresents the value and impact of higher education. Dating back to its origin in the medieval monasteries, the university has always been linked - but not yoked to economics. It would be a bitter irony if, while extending access to higher education, for centuries the sole domain of a moneyed elite, we have also invited a more monetary ethos to pervade its halls. The post-industrial managerialist state has taken an accountant's rule to the academy. In the words of authors Philip Powell and Anita Walsh, higher education has shifted, in the UK and many other countries, "from being viewed as a public good towards being regarded as a private benefit designed to enhance individual returns, best delivered through the creation of a market model".

The authors argue against privatisation and marketisation, but recognise that publicly funded institutions must do more to demonstrate the value they bring to the communities that sustain them. They point to a general mood of "public dissatisfaction with academic research" (a common refrain of populists is that academia is both out of touch with "ordinary people" and a waste of taxpayers' money), ${ }^{4}$ coupled with rising costs of higher education and reduced government funding. Powell and Walsh argue that higher education institutions (HEIs) need, in any case, to be more responsive to students and employers, and to engage more actively with local communities. To do so, they propose that HEIs follow the example of mutual organisations. Like cooperatives, these are run for the benefit of members rather than for profit, but do not pay dividends nor charge membership fees; rather, the member contributes through its relationship as a customer. A "mutualised" university engages with local communities in a series of nontransactional relationships and as part of an "ecosystem", a term the authors borrow from business research. ${ }^{5}$ The ecosystem model recognises that sustainable organisations exist in healthy symbiosis with one another. Having presented the theoretical model, the authors undertake a case study of one of Britain's oldest and most successful institutions of lifelong learning, Birkbeck College. They examine how it applies principles of mutuality to create two-way channels of engagement with the local community, and assess its impact in terms of enhancing the ecosystem.

\footnotetext{
${ }^{4}$ Ironically, it was a former UK Education Minister, Michael Gove, who stated in a Sky News television interview on 3 June 2016, during the Brexit campaign, that "people in this country have had enough of experts".

5 Ecosystems are defined by Powell and Walsh as "intentional communities of ... actors whose individual activities share, to some extent, the fate of the whole community".
} 


\section{(3) Ghanaian mature students' motivation to pursue degree programmes through distance education}

It's axiomatic that no one can be forced to learn (images of horses brought to water come to mind), yet almost everyone's experience of education is bound up with some element of coercion. It is the absence of coercion - the need to motivate the learner to attend, engage and persist - that makes adult education both so exciting and so challenging. The question of motivation is at the heart of every discussion of lifelong learning, and ought to be intrinsic to the design of every learning initiative for adults. Yet motivation is not a black-and-white issue. An adult is likely to be motivated by multiple, even competing, factors. Malcolm Knowles, a pioneer of research into adult learning, concluded that adult learners are fundamentally autonomous pragmatists, who prefer acquiring skills and knowledge that have direct and immediate relevance to their lives; their orientation is thus problem- rather than subject-centred. ${ }^{6}$ Subsequent researchers have drilled deeper into this topic, with many identifying and using the categories of intrinsic and extrinsic motivation. The authors of this study, Samuel Amponsah, Beatrice Ayorkor Torto and Samuel Kofi Badu-Nyarko, define intrinsic motivation as "the desire to learn for its own sake, for the enjoyment it provides, the learning it provides, the learning it permits, or the feelings of accomplishment it evokes", and extrinsic motivation as "[external] factors like promotion ..., salary increase, prospects for higher education, betterpaid jobs ..., approval of others and obtaining a degree". These definitions are not exhaustive, but very appropriate to a discussion of distance learning.

Distance learning has been around for nearly a century, but the Internet combined with massification of higher education has lent it new impetus. Much of the research on this topic has focused on wealthy Western countries and the development of new access modes (e.g. massive open online courses [MOOCs] and blended learning). Far less attention has been paid to the role and impact of distance learning in the socalled "developing world", despite the fact that distance learning has particular value and attraction in such countries (for example, due to larger, younger and more rural populations). The authors of this article collected data from 210 mature distance education students (aged 30+) at the University of Ghana and set out to understand what motivated them. Their findings depart from, indeed partially invert, the prevailing wisdom about adult learners' motivations; whereas adult learners are generally described in the literature as being principally motivated by intrinsic factors, Amponsah et al. found their sample at the University of Ghana were mainly extrinsically motivated, with career development the top reason given for course selection. Their findings have implications for the design of distance learning programmes in developing countries.

\footnotetext{
${ }^{6}$ For a thorough discussion of Knowles' ideas on adult learning, see Baskas, R.S. (2011). Adult learning assumptions. ERIC online submission ED517971. Retrieved 7 September 2018 from https://files.eric.ed. gov/fulltext/ED517971.pdf.
} 


\section{(4) The contributions of community learning centres (CLCs) to personal and community development in Myanmar}

As the name suggests, community learning centres (CLCs) are small-scale local institutions that support a wide range of non-formal and informal learning initiatives, from literacy to entrepreneurship, artisanship and personal development. They act as community centres, citizens' information points, theatres, libraries, museums and more. While in many parts of the world, notably Europe and the Americas, local libraries and community centres have been declining due to lack of funds and engagement, CLCs are thriving. Scattered throughout 25 countries, mostly in East Asia, are an estimated 170,000 CLCs. ${ }^{7}$ While they draw in some cases on a tradition of localised learning, CLCs are a modern phenomenon (Japan's kominkan, which established the model, were only formed after World War II) and have flourished alongside modernisation, urbanisation, rapid economic growth and ageing populations. Also, despite being a local service, CLCs have proven most successful and sustainable in those countries where the central government has demonstrated a strong commitment to lifelong learning (e.g., in Japan and the Republic of Korea) and engaged with international organisations (e.g., UNESCO, the Association of Southeast Asian Nations[ASEAN]) to operationalise it. Community Learning Centres thus provide an excellent example of "glocalism" in action. They are also varied in terms of organisation and funding, with many relying entirely on government, others entirely on non-governmental organisation (NGO) funding, and others pursuing a mixed model.

The article by Ai Tam Pham Le focuses on Myanmar, where the number of CLCs has exploded, from just seven in 1994 to more than 3,000 today. The author applies social capital theory, which seeks to quantify and valorise non-monetary community resources such as shared attitudes and values, trust, cooperation and reciprocity. She examines the contribution of CLCs to personal and community development based on fieldwork at three village CLCs in a locality $300 \mathrm{~km}$ northwest of Yangon. She gathered qualitative data by means of semi-structured interviews, focus group discussions and informal conversations, and applied them to explore the strengths, weaknesses, challenges and opportunities of these particular CLCs and of the CLC model. She also looked at the organisational structures and administrative supports provided to the CLCs. Her findings suggest that CLCs can contribute both to individuals' quality of life and communities' social capital: "Working collectively to achieve common tasks encouraged participation and cooperation for the common good of the community". CLCs also support sustainable development by providing a stable and tested network through which to channel external resources (e.g. technical or financial support) to local people.

\footnotetext{
${ }^{7}$ See Lee, R., \& Kim, J. (2016). Community-based lifelong learning and adult education: Situations of community learning centres in 7 Asian countries. Paris/Bangkok: UNESCO/UNESCO Bangkok Office. Retrieved 7 September 2018 from http://www.unesdoc.unesco.org/images/0024/002464/246480E.pdf.
} 


\section{(5) Peut-on apprendre la paix à l'école ? Une évaluation du cours "Éducation aux droits de l'homme et à la citoyenneté " (EDHC) en Côte d'Ivoire post-conflit}

\section{[Can peace be learned at school? An evaluation of a course entitled "Human Rights and Citizenship Education" in post-conflict Côte d'Ivoire]}

Following the Second World War, the idea of harnessing education to prevent such a brutal conflict recurring found ready purchase, especially with the foundation of a new international body devoted to education whose constitution explicitly states, "since wars begin in the minds of men, it is in the minds of men that the defences of peace must be constructed." ${ }^{8}$ The persistence of deadly conflict into our current century, albeit thankfully not on the scale witnessed by the last, indicates that this is easier said than done.

Côte d'Ivoire endured nearly a decade of intermittent civil strife that began in 2002 and culminated in the 2010 election crisis and brief civil war of March-April 2011. This has left the country in what the World Bank and others refer to as a "state of fragility" - neither engaged in conflict nor quite out of it either. The conflict in Côte d'Ivoire was far less bloody than those of some neighbouring countries (for example, Sierra Leone or Liberia). This, arguably, makes the task of reconciliation and peace-building less onerous but more urgent, to prevent the country sliding back into, potentially deadlier, conflict.

In 2012, the government introduced a course entitled "Human Rights and Citizenship Education" (EDHC) to the lower secondary school curriculum. This article, by Line Kuppens and Arnim Langer, looks at the needs of a post-conflict society and evaluates the intervention based on the perceptions of course participants and their teachers. The authors consider three crucial elements of peace education: the promotion of a culture of peace; a critical analysis of the violent past; and a non-authoritarian, participatory pedagogy. Their study is based on a large-scale survey, 25 focus groups and course observations carried out in Abidjan and Bouaké, the country's largest cities, beginning in 2015. They found that, despite continued enthusiasm for the course, its lack of depth, failure to directly address the Ivorian conflict, and a persistent culture of violence in schools (reflected, for example, in broad acceptance of corporal punishment and frequent disruption by violent youths), is preventing the necessary change of mentality. They eloquently sum up the limitations of the course: "Le cours se restreint au savoir seul au lieu d'une combinaison de savoir, savoir-faire et savoir-être. "9 They propose extending the course, strengthening its cross-curricular focus, and providing better teacher training to accompany it.

\footnotetext{
${ }^{8}$ See UNESCO (2015). UNESCO: Building peace in the minds of men and women [dedicated webpage]. Retrieved 7 September 2018 from https://en.unesco.org/70years/building_peace?language=en.

9 It is difficult to do justice in English to the subtle and poetic juxtaposition of savoir, savoir-faire and savoir-être. A rough translation of this sentence would be something like: "The course is limited to knowledge alone instead of being a combination of knowledge, know-how and knowing how to be [a humane person]".
} 


\section{(6) Hamburg's Family Literacy project (FLY) in the context of international trends and recent evaluation findings}

There is an expression in German, "Was Hänschen nicht lernt, lernt Hans nimmermehr", which translates literally as "What little Johnny doesn't learn, [old] John will never learn". ${ }^{10}$ The core sentiment of this idiom is still reflected in popular attitudes and public policy. Despite decades of rhetoric about lifelong learning, education in many countries continues to follow an investment model whereby children and youth are expected to absorb skills and knowledge that will serve them for life. Two realities challenge this approach. First, societies and economies are changing far too rapidly - and people are living far too long - for Hänschen's knowledge to last a lifetime. Second, we know that Hänschen's success is not separable from Hans's (one of the most consistent findings of comparative assessment studies is the link between a child's performance in school and their parents' educational level), since the generations are intertwined, not discrete. For millennia, intergenerational learning was the norm, with children and youth learning from and with their parents and grandparents. Family literacy, which was pioneered in the United States ${ }^{11}$ and has since been successfully adopted internationally, attempts to reintroduce this approach to learning in the modern school system.

The authors of this final article - Gabriele Rabkin, Stefanie Geffers, Ulrike Hanemann, Meike Heckt and Marcus Pietsch - examine the concept and application of family literacy generally, and present an evaluative case study of one programme in Germany. Known as FLY (combining acronym and metaphor), this was developed, piloted and rolled out by Hamburg's State Institute for Teacher Training and School Development with the support of the UNESCO Institute for Lifelong Learning. In 2010, the programme was awarded UNESCO's King Sejong Literacy Prize. It has three main components: parents' participation in their children's classes; special sessions for parents without their children; and joint out-of-school activities for teachers, parents and children. These three "pillars" help parents, particularly those with a migrant background, gain a better understanding of German schools and play a more active role in school life. The results of the evaluation indicate that the project's main objectives have been achieved in the participating schools: parents feel more involved in their children's learning; the quality of teaching has improved, with a more skills-based focus, better classroom management und a more supportive learning environment; and children are more likely to be exposed to environments that stimulate and enhance their literacy skills.

\footnotetext{
${ }^{10}$ Many languages have similar expressions, for example the English "You can't teach an old dog new tricks".

11 The term "family literacy" was coined by the American educator Denny Taylor in 1982. See Compton-Lilly, C. (2017). Family and home literacy across time. In G.W. Noblit (Ed.), Oxford Research Encyclopedia of Education [online]. New York: Oxford University Press. DOI: https://doi.org/10.1093/ acrefore/9780190264093.013.229.
} 